\title{
Studies the Influence of Pulsed Current and Activated Flux with TIG Welding on the Microstructure and Mechanical Properties of Stir- casted Al-SiC Composite
}

\author{
P. Sivachidambaram* and K. Balachandar \\ School of Mechanical Engineering, SASTRA University, Thanjavur - 613401, Tamil Nadu, India; \\ sivachidambaram@mech.sastra.edu,kbchandar@mech.sastra.edu
}

\begin{abstract}
In the present study, an attempt has been made to study the effect of weld parameters on as-cast Al-SiC metal matrix composite plates using a newly developed active flux composition. Stir cast Al - 8\% SiC plates were welded using different variants of TIG welding such as Constant Current TIG (CCTIG) welding, Pulsed Current TIG (PCTIG) welding, activated TIG (ATIG) welding and Pulsed Current Activated TIG (PCATIG) welding. Microstructure, macro structure, thermal profile, micro hardness and tensile properties were evaluated for different variants of TIG welding conditions and compared with each other. The combined effect of the active flux composition and pulsed current in PCATIG welding was compared with other variants such as TIG welding technique such as CCTIG welding, ATIG welding and PCTIG welding. Thermal profile revealed the increase in the peak temperature and the cooling rates for the PC-A-TIG weldments. Due to increased cooling rate, fine grain microstructure was observed in weld zone and heat affected zone. Fine grain microstructure of the PCATIG weldment is responsible for improved mechanical properties such as micro hardness, ultimate tensile strength, yield strength and elongation (\%) compared to other welding variants. Maximum micro hardness value was found in weld zone in all the variants of TIG welding. PCATIG welding showed maximum weld zone hardness as $75 \mathrm{HV}$, heat affected zone hardness values of the all TIG welding variants have more or less same value after $4 \mathrm{~mm}$ away from weld centre. Due to active flux coating on PCATIG welding lead to increase in weld depth as $4.5 \mathrm{~mm}$. This increase in the weld depth directly increase the depth-towidth ratio (D/W $=0.82$ ). Tensile strength of PCATIG welded sample showed (Ultimate Tensile Strength = 153MPa; Yield Strength $=137 \mathrm{MPa}$; elongation $(\%)=16 \%)$. It confirms that the Al-SiC composite welded using PCATIG welding were improved mechanical behaviour than other TIG welding variants such as CCTIG welding, ATIG welding and PCTIG welding.
\end{abstract}

Keywords: Al-SiC Composite, ATIG Welding, Mechanical Properties, Microstructure, PCTIG Welding, TIG Welding

\section{Introduction}

High specific strength, wear resistance, specific modulus have made Particulate Reinforced Metalmatrix Composites (PMMCs) to gain considerable applications leading to continuous research ${ }^{1-5}$ in the direction of producing new combination of PMMCs using several techniques. The PMMCs can be prepared by reinforcing the matrix through solid or liquid phase processes, of which liquid phase processes are more popular due to its ability to produce massive, low cost, industrial components ${ }^{6-8}$. Considering the advantages such as very high metal yield, range of volume fractions and no damage to the reinforcement, stir casting route ${ }^{9}$ is preferred than that of squeeze casting, spray casting and powder metallurgy routes ${ }^{10}$. Achieving uniform distribution of reinforcement

${ }^{*}$ Author for correspondence 
material, optimizing wettability, minimizing porosity in the cast metal matrix composites and avoiding chemical reactions between the reinforcement material and the matrix alloy are the factors dictating the wide range of mechanical properties ${ }^{11}$. This can be achieved by proper selection of the stir casting parameters viz. volume fractions, stirring speed, flow rate of inert gas through the melt, holding temperature, stirrer size and shapes ${ }^{9,12}$. Gas Tungsten Arc (GTA) welded light metal based components have been widely applied in various industries like automobile, aerospace, etc. It has been one of the popular methods ${ }^{13}$ due to its cleanliness, improved strength and comparatively low heat inputs than that of other arc welding processes. However, its application is restricted to thin sections because of its shallow penetration. Activated Tungsten Inert Gas welding (A-TIG) is an alternative way of welding thicker sections ${ }^{14,15}$ with sufficient weld penetration. Further, pulsed current TIG has gained wide popularity and it can be applied in actual industrial application with minimum modification in the current system ${ }^{16-18}$. The objective of this work is to study experimentally the influence of pulsed current TIG welding parameters on as-cast Al-SiCp (PMMC) plates using active flux composition developed by the research group.

\section{Experimental Work}

Few plates, each of dimension $100 \mathrm{~mm} \times 100 \mathrm{~mm} \times 10 \mathrm{~mm}$ thick were stir-cast in a permanent metal mould using commercial grade Aluminium (99.8\%). Every heat was melted in an electrical resistance stir casting furnace along with $8 \%$ wt. of preheated silicon carbide powders with an average particle size of $29 \mu \mathrm{m}$. Stainless steel stirrers were used at a rotation speed of $250 \mathrm{rpm}$. Prior to this, $1 \% \mathrm{wt}$. of magnesium powders was plunged into the melt to enhance wettability and degassed with argon atmosphere. The stir casting parameters used are as shown in Table 1. Measured average base material hardness was found to be $49 \mathrm{HV}_{500 g}$, nearly $90 \%$ more than that of commercially pure Al. Extensive study of the size \& distribution of SiC particles in Aluminium matrix was conducted by sectioning the sample at 74 places and counting the number of $\mathrm{SiC}$ particles. Then, the ratio of average surface areas of the $\mathrm{SiC}$ particles present $\left(14.24 \times 105 \mu \mathrm{m}^{2}\right.$, average $)$ to that of the aluminium matrix $\left(17.76 \times 106 \mu \mathrm{m}^{2}\right.$, average $)$ was calculated. Optical microstructure of the stir cast Al$8 \% \mathrm{SiC}$ metal matrix composite is as shown in Figure 1. Active flux $\left(\mathrm{SiO}_{2}\right)$ composition developed by the research group was mixed with acetone evenly and brush coated on specimen surface symmetrical to the weld centre line. The width of the active layer was maintained to be more than the expected arc width. Welding was carried out after the evaporation of the acetone, leaving back thin layer of active flux composition on the surface. Insitu temperature measurements were done using standard $\mathrm{K}$ - type thermocouples at $10 \mathrm{~mm}$ perpendicular to the weld centre line. The weld parameters used are as shown in Table 2.

The welded samples were cut for further micro structural and mechanical property investigation. Conventional polishing methods were utilized and the samples were etched with Keller's reagent. The optical microscopy was taken both on the weld surface and on the cross section of the samples. Micro hardness survey was conducted across the weldments and uniaxial tensile test was conducted on the welded samples prepared as per ASTM standards.

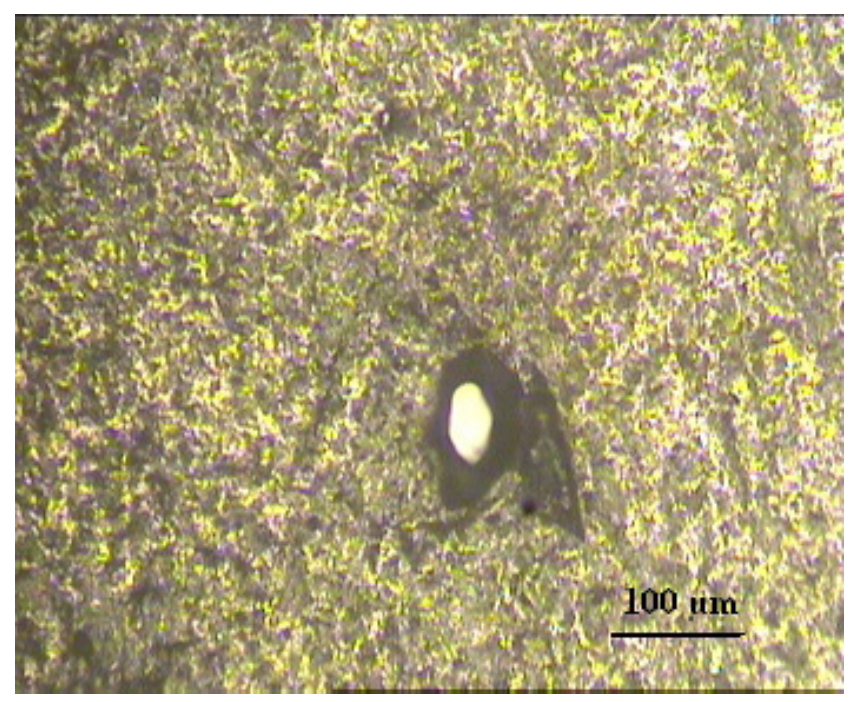

Figure 1. Microstructure for Al-8\% SiC composite.

\section{Results and Discussions}

\subsection{Time Temperature Measurements}

Thermal profile Figure 2 revealed the increase in the peak temperature in the case of activated PCTIG weldments. This increase subsequently reflected in the increased cooling rate viz. $24^{\circ} \mathrm{C} / \mathrm{s}$. While the cooling rates in the CC weldments was limited to $15^{\circ} \mathrm{C} / \mathrm{s}$, increased thermal gradients measured in the activated PC weldments resulted in $60 \%$ rise in the cooling rates. The effectiveness of active layer was predominantly observed in the increase 
Table 1. Process parameters for stir casting

\begin{tabular}{|l|c|}
\hline Process Parameter & Value \\
\hline Stirrer Speed & $350 \mathrm{rpm}$ \\
\hline Stirring Time & 600 seconds \\
\hline Preheating Time & 90 minutes \\
\hline $\begin{array}{l}\text { Stirring Temperature Preheating Tem- } \\
\text { perature of SiC }\end{array}$ & $775^{\circ} \mathrm{C}$ \\
\hline Preheating Temperature of SiC & $900^{\circ} \mathrm{C}$ \\
\hline Preheating Temperature of Aluminium & $450^{\circ} \mathrm{C}$ \\
\hline $\begin{array}{l}\text { Preheating Temperature of permanent } \\
\text { mould }\end{array}$ & $300^{\circ} \mathrm{C}$ \\
\hline SiC, Mg \& Coverall - powder feed rate & $2-3 \mathrm{~g} / \mathrm{s}$ \\
\hline
\end{tabular}

Table 2. Process parameter for TIG welding

\begin{tabular}{|l|c|}
\hline Welding Parameters & Condition \\
\hline Constant current & AC-110A \\
\hline Pulsed current & $\begin{array}{r}\text { Peak current }-160 \mathrm{~A}, \\
\text { Base current }-60 \mathrm{~A}, \\
\text { Pulse on time }-50 \%, \\
\text { Pulse frequency }-5 \mathrm{~Hz} .\end{array}$ \\
\hline Weld traverse & $120 \mathrm{~mm} / \mathrm{min}$ \\
\hline Argon flow & $18 \mathrm{l} / \mathrm{min}$ \\
\hline Active flux & $\mathrm{SiO}_{2}$ \\
\hline Active layer coating & $1 \mathrm{~g} / \mathrm{cm}^{2}$ \\
\hline
\end{tabular}

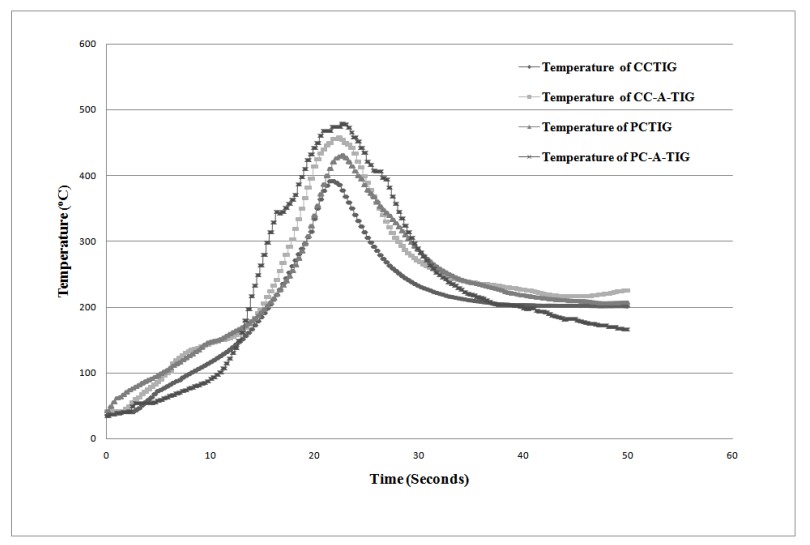

Figure 2. Thermal profile.

in the cooling rates, since higher cooling rates achieved by optimized weld parameters would result in improved mechanical properties ${ }^{16,17,19}$.

\subsection{Macro- and Micro-Structures}

The depth-to-width ratio of the various welds was measured utilizing the macrostructure of the fusion zone as shown in Figure 3 and values were tabulated in Table 3. The effect of active layer on both constant and pulsed current was found to be predominant which reflected in terms of the $\mathrm{d} / \mathrm{w}$ ratio of the fusion zone $(0.63$ and 0.82 respectively). The pulsed current combined with that of the active layer composition had its effect in changing the shape of the fusion zone $e^{20}$. This effect could be contributed to the constricted arc, the increase in the Lorentz forces during every half of the current cycle and the inverse Marangoni convection, due to the presence of the surface active layer. The constant current microstructure revealed large agglomerates of $\mathrm{SiC}$ particles.

The effect is observed particularly in the near HAZ due to the thermo-capillary convection, while the samples welded with pulsed current resulted in fine and well- distributed $\mathrm{SiC}$ particles. Figures 4 and 5 shows the microstructure of CC and PC weldments revealing effect of pulsing in the near HAZ zone.

The microstructure of the samples PC welded with surface active layer is as shown in Figure 4. The pulsed current contributed towards the lower heat input resulting in refined structure. Further, the effect of active layer aided the above mechanism through the constricted arc leading to higher $\mathrm{D} / \mathrm{W}$ ratio of 0.82 .

\subsection{Mechanical Properties}

The mechanical properties of the welded components are as shown in Table 4 . The samples welded with active surface and using PC techniques revealed better strengths

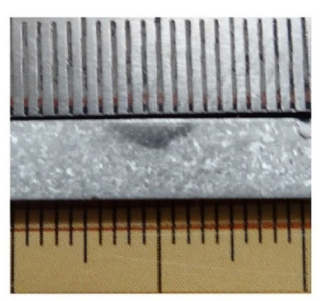

CCTIG

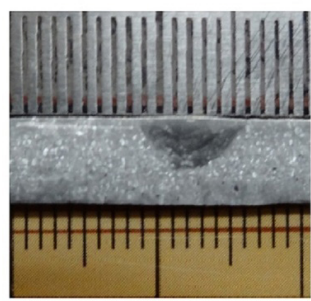

PCTIG

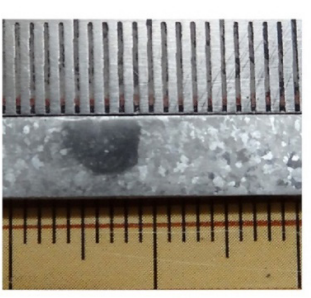

$\mathrm{ATIG}_{\mathrm{SiO}}$

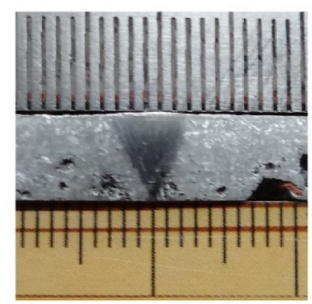

PC-A-TIG-SiO
Figure 3. Weld profile - macrostructure. 


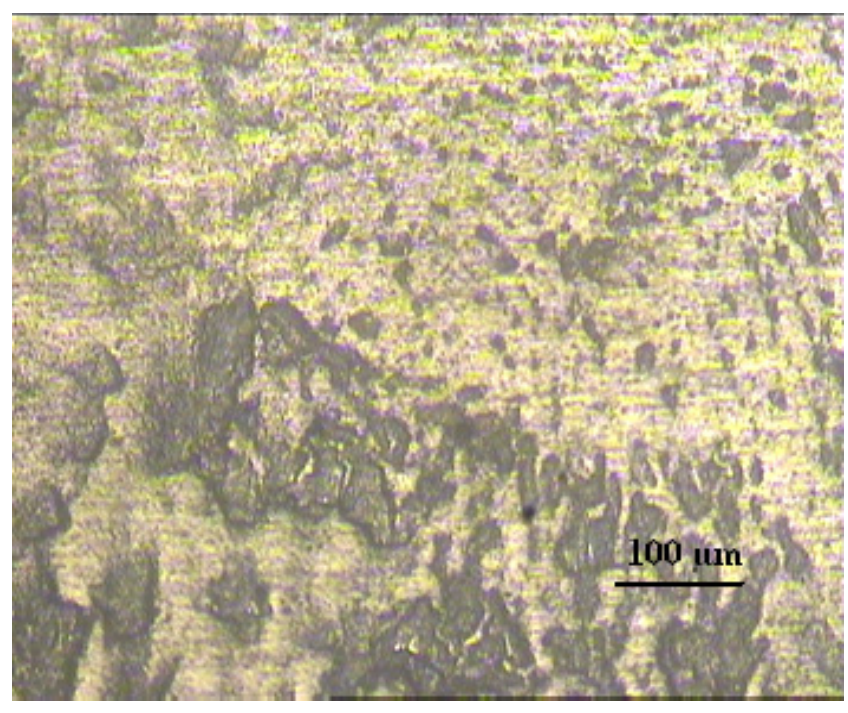

Figure 4. Microstructure for CCTIG weldment.

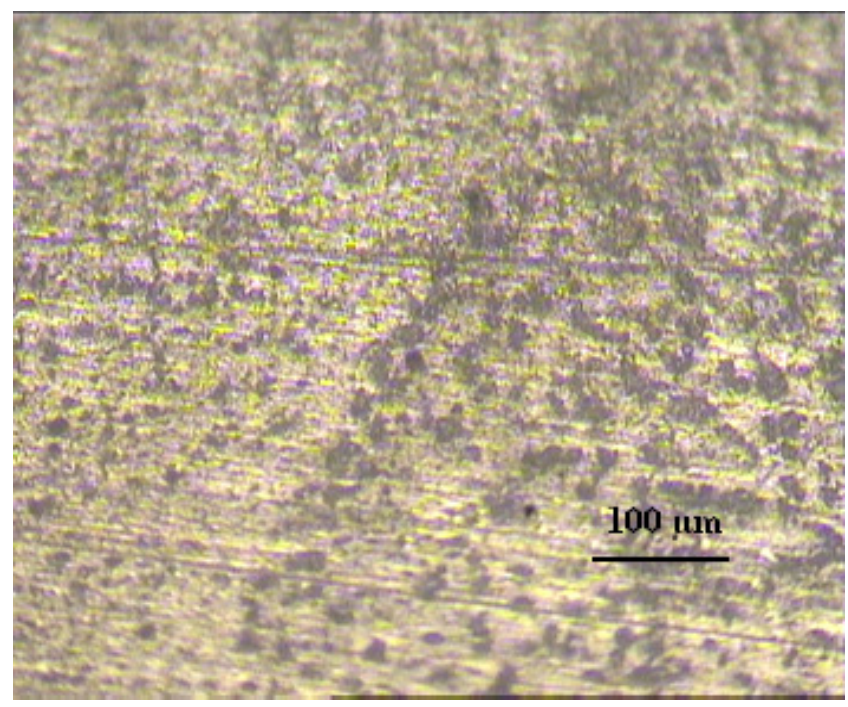

Figure 5. Microstructure for PCTIG weldment.
Table 3. Weld profile

\begin{tabular}{|l|c|c|c|}
\hline Condition & Depth $(\mathbf{m m})$ & Width $(\mathbf{m m})$ & D/W \\
\hline CCTIG & 2 & 5 & 0.4 \\
\hline ATIG & 3.5 & 5.5 & 0.63 \\
\hline PCTIG & 2.5 & 6 & 0.42 \\
\hline PCATIG & 4.5 & 5.5 & 0.82 \\
\hline
\end{tabular}

Table 4. Tensile report

\begin{tabular}{|l|c|c|c|c|}
\hline Condition & $\begin{array}{c}\text { Ultimate } \\
\text { strength } \\
(\mathbf{M P a})\end{array}$ & $\begin{array}{c}\text { Yield } \\
\text { strength } \\
(\mathbf{M P a})\end{array}$ & $\begin{array}{c}\text { Elongation } \\
\mathbf{( \% )}\end{array}$ & $\begin{array}{c}\text { Failure } \\
\text { location }\end{array}$ \\
\hline CCTIG & 108.06 & 97.2 & 11 & $\begin{array}{c}\text { Outside } \\
\text { the weld }\end{array}$ \\
\hline CC-ATIG & 126.64 & 117.72 & 14.67 & $\begin{array}{c}\text { Outside } \\
\text { the weld }\end{array}$ \\
\hline PCTIG & 123.73 & 116.04 & 14 & $\begin{array}{l}\text { Outside } \\
\text { the weld }\end{array}$ \\
\hline $\begin{array}{l}\text { PC-A- } \\
\text { TIG }\end{array}$ & 153.25 & 137.02 & 16 & $\begin{array}{l}\text { Outside } \\
\text { the weld }\end{array}$ \\
\hline
\end{tabular}

than that of the samples welded individually using continuous and PC techniques. This increase in the yield strengths could be associated with the constricted arc leading to heat source concentration and the effect of added grain refiners through the active layer composition. In addition to altering the liquid pool surface tension gradient, the major contribution was also observed on the ductility by the composition ${ }^{21}$ of this active layer. All the transverse tensile test samples failed in the base material, establishing the welds to be stronger than that of the base material. The microhardness survey done across the weldments also substantiated the same Figure 6.

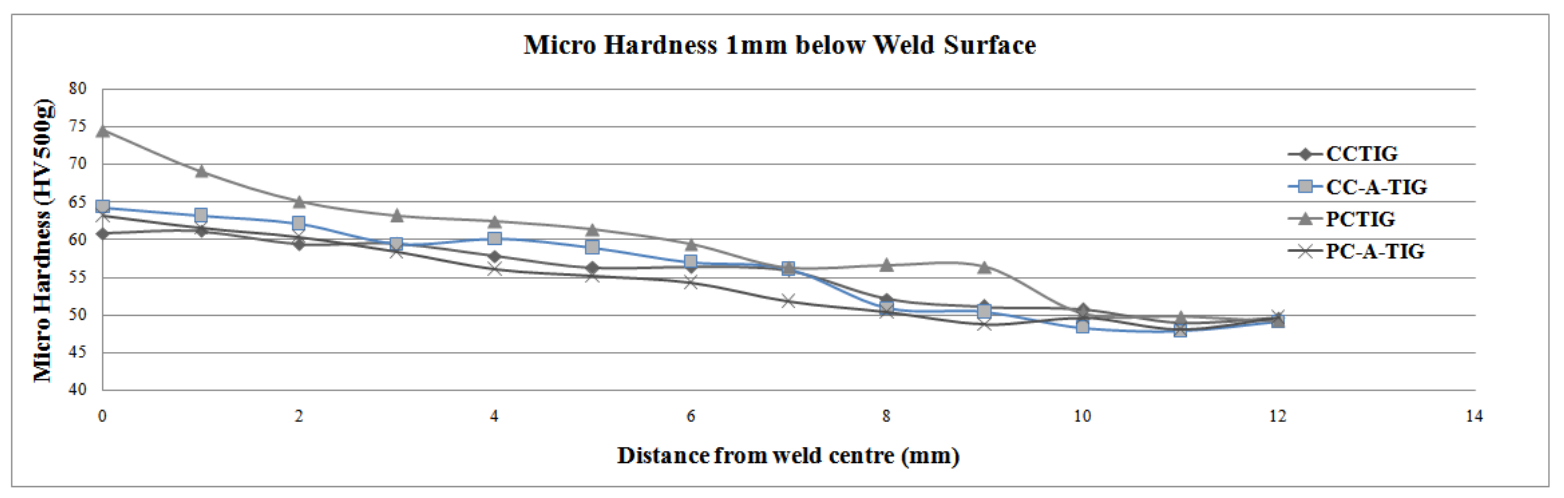

Figure 6. Microhardness. 


\section{Conclusions}

Within a chosen window of TIG welding parameters, the effect of active layer were studied on as cast Al-SiCp (MMC) plates. The influence of pulsed current TIG welding parameters also was studied in combination with the active flux composition developed by the research group. The effect of active flux composition was established in the weld dimensions (D/W ratio) and better tensile properties. In-situ temperature measurements duly substantiated the arc constriction leading to concentrated heat source and the effective role of the composition of the active layer on the mechanical properties. The increase in the weld depth-to-width ratio $(\mathrm{D} / \mathrm{W}=0.82)$ and tensile strengths (UTS = 153MPa; YS = $137 \mathrm{MPa}$; elongation = 16) were observed to be promising for the PC- ATIG welded samples.

\section{Acknowledgements}

This study was financially supported by SASTRA University $\mathrm{R} \& \mathrm{M}$ funding (SASTRA/R\&M/0028/SoME005/2012-13). The authors gratefully acknowledge SASTRA University, Thanjavur for the same.

\section{References}

1. Dinaharan I, Murugan N, Parameswaran S. Influence of insitu formed $\mathrm{ZrB} 2$ particles on microstructure and mechanical properties of AA6061 metal matrix composites. Materials Science and Engineering A. 2011 Jul; 528(18):5733-40.

2. Sarkar S, Sen S, Mishra SC, Kudelwar MK, Mohan S. Studies on aluminum - fly-ash composite produced by impeller mixing. Journal of Reinforced Plastics and Composites. 2010 Jan; 29(1):144-8.

3. Syed KH, Anuraag GP, Hemanth G, Subahan SA. Powdermixed EDM machining of aluminium-silicon carbide composites. Indian Journal of Science and Technology. 2015 Jan; 8(S2):133-7.

4. Senapati AK, Mishra PC, Routray BC, Ganguly RI. Mechanical behavior of aluminium matrix composite reinforced with untreated and treated waster fly ash. Indian Journal of Science and Technology. 2015; 8(S9):111-8.

5. Hoseini M, Meratian M. Fabrication of in situ aluminumalumina composite with glass powder. Journal of Alloys and Compounds. 2009; 471(1-2):378-82.

6. Lloyd DJ. Particle reinforced aluminium and magnesium matrix composites. International Materials Reviews. 1994, 39(1):1-23.
7. Banerji A, Surappa MK, Rohatgi PK. Cast aluminum alloys containing dispersions of zircon particles. Metallurgical Transactions B. 1983; 14(2):273-83.

8. Lei YC, Xue HL, Hu WX, Liu ZZ, Yan JC. Effects of AC arc ultrasonic on plasma arc insitu welding of SiCp/6061 Al MMCs. Science and Technology of Welding and Joining. 2011; 16(6):561-6.

9. Hashim J, Looney L, Hashmi MSJ. Metal matrix composites: Production by the stir casting method. Journal of Materials Processing Technology. 1999; 92-93:1-7.

10. Surappa MK. Microstructure evolution during solidification of DRMMCs (Discontinuously Reinforced Metal Matrix Composites): State of art. Journal of Materials Processing Technology. 1997; 63(1-3):325-33.

11. Tham LM, Gupta M, Cheng L. Effect of limited matrix-reinforcement interfacial reaction on enhancing the mechanical properties of aluminium-silicon carbide composites. ActaMaterialia. 2001 Sep; 49(16):3243-53.

12. Sozhamannan GG, BalasivanandhaPrabu S, Venkatagalapathy VSK. Effect of processing parameters on metal matrix composites: Stir casting process. Journal of Surface Engineered Materials and Advanced Technology. 2012 Jan; 2(1):11-5

13. Balachandar K, Sarma VS, Bhanu P, Phanikumar G. Microstructure and mechanical properties of GTA Welded Ti-15-3 beta titanium alloy. Metallurgical and Materials Transactions A. 2009 Nov; 40(11):2685-93.

14. Liu L, Zhang Z, Song G, Shen Y. Effect of cadmium chloride flux in active flux TIG welding of magnesium alloys. Materials Transactions. 2006 Feb; 47(2):446-9.

15. Leconte S, Paillard P, Saindrenan J. Effect of fluxes containing oxides on tungsten inert gas welding process. Science and Technology of Welding and Joining. 2006 Feb; 11(1):43-7.

16. Balasubramanian V, Ravisankar V, Madhusudhan Reddy G. Influence of pulsed current welding and post weld aging treatment on fatigue crack growth behaviour of AA7075 aluminium alloy joints. International Journal of Fatigue. 2008 Mar; 30(3):405-16.

17. Karunakaran K, Balasubramanian V. Effect of pulsed current on temperature distribution, weld bead profiles and Effect of pulsed current on temperature distribution. Transactions of Nonferrous Metals Society of China. 2011 Feb; 21(2):278-86.

18. Balasubramanian V, Ravisankar V, Madhusudhan Reddy G. Effect of pulsed current and post weld aging treatment on tensile properties of argon arc welded high strength aluminium alloys. Materials Science and Engineering A. 2007 Jun; 459(1-2):19-34.

19. Balasubramanian V, Ravisankar V, Madhusudhan Reddy G. Effect of pulsed current welding on fatigue behaviour of high strength aluminium alloy joints. Materials and Design. 2008; 29(2):492-500. 
20. Xu YL, Dong ZB, Wei YH, Yang CL. Marangoni convection and weld shape variation in ATIG welding process. Theoretical and Applied Fracture Mechanics. 2007 Oct; 48(2):178-86.
21. Heiple CR, Roper JR. Mechanism for minor element effect on GTA fusion zone geometry. Welding Journal. 1982 Apr; 61(4):143s-5s. 